\title{
La publicidad, la autorregulación \\ y sus repercusiones sociales
}

Carola García Calderón'

E

N LOS ÚlTIMOS AÑos a nivel mundial las políticas de autorregulación en diversas áreas han avanzado, lo mismo sucede en el ámbito de la publicidad. En el caso de México la desregulación en materia de publicidad se inició con las modificaciones al Reglamento de Control Sanitario de la Publicidad en 1993, durante el gobierno de Carlos Salinas de Gortari; con la promulgación del nuevo Reglamento de Ley General de Salud en Materia de Publicidad (4-05-2000), la tendencia parece consolidarse hasta en la publicidad de productos que antes había sido sometida a mayores controles, como la de los tabacos, las bebidas alcohólicas y los medicamentos.

Los cambios efectuados a la Reglamentación de la publicidad de los productos relacionados con la salud, se inscriben en la política desregulatoria emprendida por el gobierno mexicano, la cual a su vez es producto del proyecto neoliberal. El marco para la desregulación que se anunció bajo el lema "regular menos, para regular mejor", está dado por la apertura del mercado, la globalización de la economía a nivel mundial y la firma del Tratado de Libre Comercio. El país se abrió al mercado y a la inversión extranjera, el ingreso en 1986 al Acuerdo General de Aranceles y comercio (GATT) y la firma del TLC con Estados Unidos y Canadá muestran tal apertura. El liderazgo económico lo tiene la inversión privada, ha crecido la importación y las exportaciones son mayores por las filiales de las transnacionales que de firmas nacionales; del mismo modo la llegada y explotación de franquicias evidencian las tendencias económicas.

La política de adelgazamiento del gobierno mexicano y la venta de paraestatales, ${ }^{2}$ complementan el panorama de la política neoliberal, la cual ha llevado a modificar la

1. Profesora Titular C, Facultad de Ciencias Políticas y Sociales, UNAM.

2. El informe sobre la situación social en el mundo en 1993 de la ONU, indica que el total de empresas paraestatales en México bajó de 1155 en 1982, a 132 en enero de 1992. El Estado se deshizo de más 
reglamentación en materia de inversión extranjera y en diversas áreas de la economía. La economía de mercado se plantea como libre de la interferencia gubernamental; el gobierno, al contrario, debe eliminar trabas a nivel reglamentario y burocrático para el desarrollo del mercado y deshacerse de todo tipo de subsidios y reglamentos proteccionistas.

El modelo de sustitución de importaciones es reemplazado por una economía de mayores ventajas competitivas, en la que el libre juego de la oferta y la demanda determina nuevas reglas para la inversión. Al plantearse el mercado como un intercambio libre e informado en las tesis neoliberales, el mercado también es visto como justificación de una organización social libre, de la que se desprenden los planteamientos de las organizaciones internacionales de la publicidad que emprendieron desde la década de los ochenta una lucha por la "libertad de expresión comercial", sustentada en la premisa de que el consumidor tiene derecho a que se le proporcione la información comercial sin ninguna limitante y bajo la idea de que si se permite producirlo no debe restringirse el anunciarlo, como repetidamente han sostenido los productores de tabaco ante el avance de reglamentaciones que los excluyen de anunciarse en ciertos medios de comunicación.

Esto se traduce en buscar la promulgación de códigos de ética y la autorregulación en lugar de reglamentos y autorizaciones gubernamentales: "El único sistema que tenemos para preservar la libertad de expresión comercial es la autorregulación... Dentro de un régimen de autorregulación hombres y mujeres, desde agencias de publicidad, empresas anunciantes y medios de comunicación, producirán una publicidad seria, respetuosa y honesta que no defraude la confiabilidad del receptor del mensaje". 3

\section{Las organizaciones a favor de la autorregulación}

El poder económico de la publicidad se ha hecho acompañar por organismos de cohesión y defensa de anunciantes y publicistas, que han sido elementos eficaces para negociar la promulgación de reglamentos y para frenar acciones gubernamentales coercitivas. Esta acción emprendida a nivel mundial apunta al fortalecimiento

de mil compañias en 10 años, de manera que el país es líder de privatizaciones en América Latina y cuarto lugar a nivel mundial. El financiero, 28 de julio de 1993, p. 4.

3. Zuazua de Giagioni, R. "La preservación de la libertad de expresión comercial a través de la autorregulación". Ponencia presentada en el 34 Congreso Mundial de la International Advertising Association. México, mayo de 1994. 
de este tipo de organizaciones que impulsen la defensa contra las regulaciones gubernamentales. El discurso por la autorregulación en materia de publicidad ha tenido su mayor promoción por la International Advertising Association (IAA), a nivel mundial, y en América Latina por la Sociedad Interamericana para la Libertad de Expresión Comercial (SILEC).

La IAA es el más influyente organismo de la publicidad en el mundo, por su cobertura geográfica y por el poder económico de sus integrantes; cuenta con representaciones en más de 90 países, opera én todos los continentes, agrupa a las principales agencias de publicidad del mundo, a los anunciantes que en su mayor parte son grandes consorcios y empresas globales y a las grandes cadenas de comunicación. ${ }^{4}$ Los miembros de la IAA representan el 97 por ciento del gasto publicitario a nivel mundial. Opera como organismo rector de las organizaciones nacionales que lo componen, de manera que sus políticas y recomendaciones son adoptadas por los capítulos de cada país afiliado.

La SILEC es una asociación regional que se constituyó en Caracas en 1992, con 14 países de América Latina, busca cohesionar a nivel continental a las asociaciones locales contra cualquier intento de restricción. En su primera reunión de trabajo (1993), se planteó como meta crear un sistema de autorregulación "para demostrarle a los gobiernos que hay capacidad para hacer publicidad dentro de los parámetros de veracidad, seriedad y buen gusto". Este organismo juega con los mismos temores que han alimentado a la industria publicitaria en los últimos años: "Hoy se está atacando por igual, como en una onda expansiva a la publicidad para productos farmacéuticos, alimentos, detergentes, autos, juguetes, seguros de vida. Si no nos cuidamos y hacemos un frente común, un día de estos, la publicidad correrá el riesgo de desaparecer". ${ }^{5}$ Los esfuerzos de la SILEC se traducen ya en varios códigos de ética de sus países afiliados; en el caso de México, donde el código existe desde 1988, se ha avanzado con la creación en 1994 del Consejo Nacional de Autorregulación que pretende constituirse en un órgano privado encargado de dirimir conflictos.

En México, el interés por contar con códigos de Etica data desde las primeras organizaciones de publicistas, en 1987 la Asociación Mexicana de Agencias de Publicidad (AMAP) elaboró un código de ética publicitaria, manifestando su preocupación por la responsabilidad de la industria. El Código de Etica se propuso para ser observado por la industria publicitaria y no como una sustitución de la reglamenta-

4. Cfr. García Calderón, Carola, "El poder de la publicidad en México", Tesis doctoral, FCPyS., UNAM, 1996, pp. 185-194.

5. Apertura. Año 3, n. 2. Febrero de 1993, p. 56. 
ción; su alcance se reducía a las agencias miembros de la AMAP y muchos de sus señalamientos no eran observados en la publicidad en general. Este código fue tomado como base para el Código de Etica Publicitaria suscrito por los organismos integrantes del Consejo Nacional de la Publicidad, el 27 de septiembre de 1988. La adopción de códigos de ética es considerada como una acción básica para evitar mayores reglamentaciones, pero no todos los publicistas se pliegan a sus principios, como se ha podido observar en la publicidad comparativa y en otros casos. A pesar de esto, los códigos son presentados como la opción para liberarse de regulaciones y se busca su implantación a nivel regional y mundial.

Estos organismos han emprendido campañas para difundir el papel que la publicidad juega como financiamiento de los medios de comunicación, en el patrocinio de eventos deportivos, la creación de empleos, su contribución a la economía y al mercado. Desde mediados de 1990 la IAA elaboró una campaña mundial cuyo lema es "Publicidad: el derecho a elegir". En México la campaña señalaba: "Cuando la publicidad hace su trabajo, millones de personas conservan el suyo", "Sin el ingreso generado por la publicidad este dinero debería venir de otro lugar. Como el costo de su boleto. Lo que podría quitarle lo divertido a cualquier partido".

\section{De la reglamentación a la autorregulación}

La reglamentación en materia de publicidad se dio de manera posterior al desarrollo de la industria publicitaria; si bien desde 1955 en el Código Sanitario se hacía referencia a la publicidad y también en la Ley Federal de Radio y Televisión, los primeros ordenamientos específicos se promulgaron en los años setentas, cuando esta industria se hallaba ya estructurada en cuanto a capitales, objetivos y contenidos, lo cual dio lugar a lagunas legales, ausencias, duplicación de competencias o desconocimiento gubernamental en cuanto a las características, la técnica y el contenido de los mensajes. La primera reglamentación de carácter específico fue el Reglamento para la Publicidad de Alimentos, Bebidas y Medicamentos (1974), promulgado durante el gobierno de Luis Echeverría que destacaba la preocupación por los daños a la salud, la ingestión de bebidas alcohólicas y el consumo de tabaco y la necesidad de proteger la adecuada salud individual y colectiva. Posteriormente en 1986, se sustituyó este reglamento por el de Control Sanitario de la Publicidad que tenía un mayor grado de claridad, abarcaba los diversos rubros de la publicidad de productos relacionados con la salud y volvía a condicionar su autorización a la autorización previa por parte de la Secretaría de Salud. Antes de la aprobación del RCSP fue 
notoria la presión de la industria publicitaria, desde 1983 previo a la aparición de la Ley General de Salud hasta la fecha en que se aprobó el nuevo Reglamento. ${ }^{6}$

La lucha por la flexibilización de la reglamentación a nivel nacional obtuvo resultados al modificarse la Ley General de Salud en 1991, en su artículo 301 establecía que sólo requerirían de autorización previa la publicidad de tabacos, bebidas alcohólicas, insumos para la salud y otros productos que pudieran poner en riesgo la salud. Esto eliminaba la autorización previa para la publicidad de alimentos (incluso los de bajo valor nutritivo), productos de higiene y aseo, de bebidas no alcohólicas, medicamentos de los que se expenden sin receta, entre otros. A partir de tales enmiendas, se iniciaron los estudios para un nuevo RCSP. En una reunión con la IAA, la subsecretaria de Regulación y Fomento Sanitario de la SSA dio a conocer las acciones que se estaban emprendiendo para simplificar y desregular el control de la publicidad "pero sin menoscabo de las normas de protección y fomento a la salud de los consumidores". ${ }^{7}$ Dentro de las acciones de la Subsecretaría de Regulación, se contempló el diálogo permanente con anunciantes, publicistas, directores de medios e interesados en general "con objeto de que de manera concertada se sienten las bases de las reglas del juego que habrán de regir en torno a esta nueva reglamentación".

Ante el anuncio de elaborar un nuevo Reglamento, el Instituto Nacional del Consumidor demandó "una mayor y más severa restricción a la difusión publicitaria del alcohol y el tabaco a través de la radio y la televisión", planteó imponer trabas al patrocinio de eventos, aduciendo que este tipo de anuncios tienden a desaparecer en un número cada vez más amplio en distintos países donde tal medida ha sido apoyada por la Organización Internacional de Uniones de Consumidores. ${ }^{9}$

Por parte del ámbito publicitario, las primeras opiniones aventuraban "un fatídico retorno a una posible prohibición para publicitar ciertos productos que encabezan los cigarros, los licores y las toallas higiénicas para mujer". "Muy a pesar de la aparente buena voluntad de las autoridades sanitarias que han dialogado con las agencias publicitarias, existe la presión de otras dependencias como la Secretaría de Gobernación, la SECOFI y la propia presidencia de la República, que tienen en la mira de sus rifles, sobre todo a la publicidad de cigarrillos". ${ }^{10}$

Estas posiciones encontradas resumen las dos posiciones que generalmente se manifiestan al respecto, una por un mayor control de cierto tipo de publicidad y otra

6. Sobre las diversas presiones, desde campañas de rumores hasta la negociación específica de algunos artículos del Reglamento, cfr. Garcia Calderón, Carola. Op. cit., Capitulo 3.

7. Memoria de la International Advertising Association. Capitulo México. 1994, p. 45.

8. "Avances positivos de la Secretaría de Salud". El financiero, 26 de junio de 1991, p. 20.

9. El Universal, 10 de marzo de 1991, p. 26-A.

10. De Vivar, R. "Los anuncios para cigarros en la mira del rifle”. El Financiero, 2 de mayo de 1991, p. 33. 
por la flexibilización, generalmente, la que se ha impuesto es la segunda o se ha establecido una negociación que lleva a los anunciantes a aceptar algunas restricciones a cambio de la autorregulación en otros aspectos, como se verá en el nuevo reglamento aprobado en el año dos mil.

En el caso de las modificaciones al reglamento en 1993, los anunciantes y publicistas buscaron destacar estudios realizados en otros países para tratar de demostrar la inutilidad de restringir la publicidad (sobre todo la de bebidas alcohólicas): "Las prohibiciones publicitarias no funcionan, no sólo en México, sino en ninguna parte del mundo... La empresa de investigaciones Osborne \& Smart realizó profundas encuestas entre todos los núcleos de la población estadunidense y después de estudiar los efectos de las restricciones de anuncios de licores, llegaron a la siguiente conclusión: Ha quedado demostrado que prohibir la publicidad de bebidas alcohólicas no disminuye el consumo".

Finalmente, las modificaciones al RCPS se tradujeron en un paulatino abandono de la responsabilidad gubernamental al liberar a la publicidad de la autorización previa, como se señalaba en la Ley General de Salud, al retirarse ésta, toda la publicidad pasó a ser en la práctica No regulada, ya que los mecanismos de vigilancia no se incrementaron y si antes ya eran insuficientes para verificar el cumplimiento de la ley, quedaron completamente rebasados ante el abundante volumen de publicidad. En las reformas al Reglamento en 1993, se hizo evidente como las políticas adoptadas por el gobierno mexicano ha sido correspondientes con las tendencias globalizadoras y con la lucha de las organizaciones mundiales de la publicidad por la autorregulación; lo cual ha conducido a una virtual desregulación; esto deja ver la falta de interés de parte del gobiemo para poner límites a la publicidad y dejar de lado aspectos relevantes como la publicidad destinada a los niños o aquella que contribuye a modificaciones importantes en la ingesta alimentaria. La discusión sobre la publicidad ha sido planteada, como se ha visto ante la formulación o la revisión de su reglamentación, únicamente entre el sector privado y las dependencias gubernamentales, de manera tal que la coincidencia de políticas ha llevado a flexibilizar las restricciones, como se observa en el nuevo Reglamento de Publicidad.

\section{El Reglamento de la Ley General de Salud en Materia de Publicidad}

El 4 de mayo del año 2000 se publicó en el Diario Oficial de la Federación el nuevo Reglamento de Publicidad de la Ley General de Salud, este nuevo ordenamiento 
retoma en términos generales lo establecido en el reglamento anterior, mantiene las limitaciones en materia de tabacos, bebidas alcohólicas y productos de riesgo para la salud y contiene adecuaciones en relación a los patrocinios, el Consejo Consultivo de la Publicidad, además de que incorpora un título en materia de Códigos de Etica.

El nuevo reglamento resulta más específico que los anteriores, en cuanto a que por primera vez se cuenta con una definición dentro del texto de lo que se entiende por: publicidad, patrocinio, medio de difusión, campaña publicitaria, agencia de publicidad, anuncio publicitario, anunciante y artículo promocional; términos que no se definían con anterioridad y que daban lugar a interpretaciones diversas, aparece ya en este reglamento la integración de la marca como parte de la publicidad, no como en las reglamentaciones anteriores donde no se consideraba la marca como publicidad.

Mantiene lo relativo a que la publicidad deberá ser orientadora y educativa y cuando se considera que no es comprobable, (artículos 6 al 9), además agrega, en su artículo octavo, que no se podrá realizar publicidad que atente o "ponga en riesgo la seguridad o integridad física o mental o dignidad de las personas". Este señalamiento recupera una parte que se había eliminado en 1993 del RCSP donde se ponía énfasis en la dignidad de las personas en especial de la mujer.

En cuanto a las leyendas, el Reglamento precisa consideraciones sobre tamaño en anuncios de radio y televisión, espectaculares e impresos. En el caso de la publicidad difundida por radio, establece que serán parte integral del anuncio y se pronunciarán al mismo ritmo y volumen de voz del anuncio (Art. 10-III) y no con la lectura rápida con que se acostumbraba leerlas. Contempla también las leyendas en la publicidad que aparezca en los medios informáticos o de telecomunicación.

En correspondencia con la Ley Federal de Radio y Televisión, el nuevo Reglamento establece el horario para la difusión de bebidas alcohólicas y tabacos: "Solo podrán transmitirse en los horarios autorizados por la Secretaría de Gobernación y en las salas cinematográficas sólo en películas correspondientes a las clasificaciones C y D". (artículo 33). Si bien en los reglamentos anteriores se remitía a esos ordenamientos, sólo se cumplía en televisión el iniciar la transmisión a las 22 y 21 horas, respectivamente, pues en la radio (aunque la ley establecía el mismo horario) se transmitía este tipo de publicidad durante todo el día.

El Título Décimo Tercero del Reglamento establece que la Secretaría de Salud promoverá la formulación de códigos de ética entre los colegios, asociaciones y consejos que agrupen a quienes se dedican o tienen relación con la publicidad y plantea que podrá celebrar convenios con anunciantes a partir del establecimiento de códigos, "a fin de otorgar facilidades a los suscriptores" (artículo 100), tales como conceder un permiso de publicidad en cinco días, en lugar de los 20 días que establece 
el reglamento (artículo 80) o de exentar de la presentación de aviso a la autoridad en la publicidad de alimentos, bebidas no alcohólicas e insumos para la salud (artículo 86).

A esto se suma, dentro de las disposiciones generales para bebidas alcohólicas y tabaco, que la SSA con la participación de los sectores público, privado y social, promoverá y apoyará, la elaboración y difusión de campañas publicitarias orientadas e la moderación en el consumo de las bebidas alcohólicas y desalentar el consumo de tabaco entre la niñez, la juventud y durante el embarazo (artículo 30).

El punto que generó mayor controversia fue el relativo al patrocinio de eventos por los productores de bebidas alcohólicas y tabaco. Ante el anuncio de un nuevo Reglamento de Publicidad, desde 1999 se inició un debate en relación con el patrocinio de eventos deportivos, sobre todo en el medio del automovilismo, del tenis, del fútbol y las corridas de toros que se han sostenido con los recursos publicitarios que permiten la realización de torneos, el otorgamiento de premios y que remiten a la publicidad en estadios y en transmisiones televisivas; la discusión entre autoridades gubernamentales y anunciantes y publicistas culminó en una serie de restricciones para el patrocinio, pero a su vez en la posibilidad de aceptar convenios especificos entre ambas partes, lo que ha dado lugar al inicio de ellos. Se firmó ya el de la industria cervecera y está por signarse el de la industria tabacalera. El reglamento prohibió a los productores de bebidas alcohólicas patrocinar eventos deportivos, sólo podrán patrocinar eventos creativos (artículo 31); en el caso de bebidas alcohólicas de baja graduación sí podrán patrocinar ambos tipos de eventos. Las bebidas alcohólicas y los tabacos no podrán patrocinar eventos relacionados con actividades practicadas preponderantemente por menores.

El 8 de junio del 2000, la Secretaría de Salud y la Asociación Nacional de Fabricantes de Cerveza firmaron un convenio para establecer compromisos adicionales a la reglamentación en materia de la publicidad. El secretario de Salud y los dirigentes de las dos empresas cerveceras que controlan el mercado: Fomento Económico Mexicano (FEMSA) y Grupo Modelo, acordaron acciones para desalentar la "barra libre", sobre todo en sitios donde se reúnen jóvenes, implantar campañas contra el abuso en el consumo y que los anuncios de marcas de cervezas en las vestimentas deportivas sean aún de un tamaño menor a lo autorizado en el reglamento. El reglamento establece que el tamaño de los emblemas o logotipos en las camisetas no sea mayor a una sexta parte de la superficie posterior de las mismas (artículo 34-X).

En el mes de junio, los anunciantes de tabaco dieron a conocer su Código de Ética para autorregularse y comprometerse a elaborar una campaña en sitios de venta y en carteles para evitar que se vendan cigarros a menores de edad, en el código están de acuerdo las principales empresas que controlan el mercado nacional: Phillip Morris, La moderna-British Tobacco y La Libertad (Milenio, 30 junio del 2000). 
Sin embargo, los avances en la regulación y la firma de convenios específicos no se traducen en acciones reales ante los volúmenes de publicidad; la presencia de la publicidad ha formando pautas de consumo durante años y ha vinculando los productos con características que los hacen atractivos a los consumidores; la integración del mercado se traduce en campañas de una expresión corporativa a nivel global que diseña, produce y difunde la mayor parte de los mensajes e imaginarios sociales como financiamiento de la industria de la comunicación y parte de los nervios del consumo.

\section{La publicidad de cerveza}

Aun cuando no se ha logrado establecer con exactitud la manera como la publicidad repercute sobre el consumo de bebidas, sí es posible afirmar que su existencia ha contribuido a la ampliación del mercado a la elevación en su consumo. En el caso de la cerveza, Víctor Manuel Bernal Sahagún (1983) consignaba que en 1925 el consumo de cerveza por persona al año en el país era de 3.5 litros; para 1945 había llegado a 14.1 litros, en 1965 alcanzaba los 22.7 litros y en 1980 ya se había incrementado a 40 litros. ${ }^{11}$

\begin{tabular}{|l|l|}
\hline $\begin{array}{l}\text { Ron y brandy, 24 por ciento } \\
925 \text { millones de dólares }\end{array}$ & $\begin{array}{l}\text { Bacardí, 90 por ciento } \\
\text { Domecq, 80 por ciento }\end{array}$ \\
\hline $\begin{array}{l}\text { Tequila, 4 por ciento } \\
170 \text { millones de dólares }\end{array}$ & $\begin{array}{l}\text { Cuervo y Sauza } \\
\text { Grupo Modelo 55 por ciento }\end{array}$ \\
\hline $\begin{array}{l}\text { Cerveza, 67 por ciento } \\
2 \text { mil millones de dólares }\end{array}$ & $\begin{array}{l}\text { FEMSA } \\
43 \text { por ciento }\end{array}$ \\
\hline
\end{tabular}

Los datos de 1993 mostraban que el consumo alcanzaba los 48 litros por persona al año. ${ }^{12}$ Según datos publicados en el presente año, en 1999 el consumo promedio llega a los 50.6 litros, lo cual representa un gasto per cápita de 809 pesos, equivalente al 83.4 por ciento de un mes de salario mínimo. Comparativamente el consumo es

11. Bernal Sahagún, Víctor Manuel, El alcoholismo en México, Nuestro Tiempo, México, 1983.

12. El Financiero, Febrero 16 de 1994, p. 15. 
La publicidad, la autorregulación y sus repercusiones sociales

menor en relación con Estados Unidos, Gran Bretaña y Alemania, donde alcanza 95, 115 y 142 litros al año; en Colombia y Venezuela el consumo asciende a 64 y 71 litros, respectivamente. México ocupa en la actualidad el séptimo lugar como productor de cerveza, la cerveza constituye el 67 por ciento del total del consumo en el mercado de bebidas alcohólicas en el país.

El mercado de bebidas alcohólicas en Estados Unidos representa más de 23 mil millones de dólares con una tendencia a la contracción debido a las restricciones legales vía impuestos que están orillando a un menor consumo; en tanto el mercado de bebidas alcohólicas en México está creciendo y resulta atractivo para la comercialización de cerveza, brandy, ron y tequila. Dicho mercado asciende a 4 mil millones de dólares y se distribuye de la siguiente forma: ${ }^{13}$

El resto del mercado se constituye por whisky, cognac, vodka, vinos de mesa, cremas y licores. El medio más empleado para la publicidad de bebidas alcohólicas es la televisión, donde se anuncia cerca del 76 por ciento del volumen publicitario de este tipo de productos.

De las veinte marcas de cerveza que se producen en el país, las principales pertenecen a los dos grupos que controlan el mercado: FEMSA, producto de la fusión de Cervecería Cuauhtémoc de Monterrey (Carta Blanca) y Moctezuma de Orizaba, que además es parte del Grupo Visa. El Grupo Modelo, productor de Corona se asoció hace pocos años con Anheusser-Busch, productor de la cerveza Budweisser, que posee el 18 por ciento de las acciones de Modelo.

El sistema de distribución es básico para el consumo de estos productos, se facilita su adquisición al estar disponibles en expendios, tiendas de abarrotes, vinaterías y supermercados y al consumirse también en fondas, bares, restaurantes, discotecas y centros nocturnos. De alguna manera, el extendido número y la variedad de centros de venta junto con la publicidad, colaboran a la comercialización y a la ampliación del consumo dentro de sectores sociales específicos. Así se observa que en las discotecas los jóvenes de nivel socioeconómico alto y medio prefieren tomar ron o brandy, lo cual corresponde con la publicidad que muestra personajes jóvenes en esos sitios.

El estudio del Instituto Nacional del Consumidor ${ }^{14}$ estimaba que los modelos masculinos que aparecen en la publicidad de bebidas representan entre 36 y 45 años, en tanto los modelos femeninos son más jóvenes; pero cuando se presentan en grupo la edad que aparentan fluctúa entre los 25 y 35 años y "ríen, bailan y disfrutan de la

13. Datos de Casa de Bolsa Bancomer, en El Financiero, Febrero 4 de 1994.

14. "La publicidad de Bebidas alcohólicas", en Revista del Consumidor, Febrero de 1990. Reporte especial. 
vida". Un estudio de International Research de México (1994) expone las imágenes con que se asocia a las bebidas alcohólicas:

- El whisky se identifica como bebida cara, exclusiva, importada de calidad, para personas mayores y ocasiones formales.

- La cerveza se ubica como bebida fresca, suave, de precio accesible, para ocasiones informales, se toma con amigos.

- El tequila es considerado como bebida fuerte, de calidad, nacional, para tomarse con amigos.

- El ron es una bebida combinable, para tomarse con amigos.

Estas imágenes enunciadas por los consumidores, se relacionan con las propuestas de la publicidad que destacan en los comerciales de cada producto, los mensajes de cerveza se ambientan en días de campo, estadios de futbol, en la casa frente a la televisión viendo el futbol o en restaurantes. A lo largo de los años los mensajes de cerveza han manejado la asociación con el deporte, principalmente el box y el fútbol; algunas marcas de cerveza han recurrido a cómicos populares; las cervezas claras han empleado la imagen femenina - basta recordar la rubia superior con el jingle "la rubia que todos quieren"- que aludía a la mujer y la cerveza.

La actual reglamentación prohibe relacionar las bebidas alcohólicas con el deportista, artista o evento a patrocinar; difundir testimonios o intervenciones relacionados con el consumo de los productos por parte de celebridades o figuras públicas de reconocido prestigio (artículo 31-II y 31-VI). Un avance en la reglamentación es que antes se restringía la aparición de deportistas, ahora además se agrega que no se utilice a deportistas o a personas con vestuario deportivo (artículo 34-IX).

En los últimos años, con el surgimiento de las cervezas ligeras, la publicidad se ha orientado hacia los jóvenes (la legislación desde 1986 prohibe asociarlas con menores de 25 años), pero los ambientes en que se presenta la publicidad en discotecas, fiestas y reuniones informales, al igual que con los mezcladores y las bebidas de baja graduación, como las piñas coladas, los cocteles y los coolers, cuyo lanzamiento se dio en horarios de televisión por la tarde con el lanzamiento del concurso Valores Juveniles de Bacardí. La publicidad se dirige a los jóvenes interesados en el concurso y en la música, al tiempo que se promovía una bebida suave y colocaba la marca Bacardí en horarios restringidos para bebidas de alta graduación. Con la reglamentación actual, las bebidas alcohólicas de alta graduación no podrán patrocinar este tipo de eventos y la marca ya queda establecida como recurso publicitario. 


\section{La publicidad de tabaco}

Otro ámbito donde la publicidad ha conformado pautas de consumo a lo largo de mucho tiempo ha sido en lo relativo al tabaco, las primeras empresas radiofónicas surgieron con su patrocinio y durante años ha promovido asociaciones con imágenes de virilidad, sexualidad o éxito; la publicidad de tabaco destaca muchas de las motivaciones que llevan a los hombres a fumar: desde el acceso a mundos y espacios limitados a otros: el mundo de los adultos, el mundo masculino, el mundo de los negocios y su asociación a figuras cinematográficas como un Bogart, un Alain Delon o un James Bond. Durante años nos hemos acostumbrado a ver su asociación con libertad, virilidad o naturaleza, con el hombre Marlboro; los cigarros para hombres rudos o "muy hombres" o para mujeres atrevidas, para los jóvenes que se divierten (en los anuncios de Boots y Pall Mall), para personas que realizan una actividad creativa o presentados como símbolos de distinción y exclusividad de una clase (Benson \& Hedges). En los cigarrillos, al igual que en toda la publicidad, no se ven situaciones desagradables, nadie padece los efectos del tabaco ni los no fumadores protestan. Las únicas referencias a sus consecuencias son las leyendas que por ley desde hace años se incluyen: "Este producto es nocivo para la salud", "Fumar es un factor de riesgo para el cáncer y el enfisema pulmonar", "Fumar durante el embarazo aumenta el riesgo de parto prematuro y de bajo peso del producto". Leyendas que generalmente aparecen en letras pequeñas o se leían rapidísimo en voz del locutor, esto se precisó más en el Nuevo Reglamento de Publicidad y se recuperaron las restricciones establecidas en los reglamentos anteriores, como que no se puede consumir o aparentar el consumo en la publicidad, no dirigirse a menores de edad, la edad que aparenten los modelos sea mayor de 25 años. El horario que se establece en el actual reglamento recorre su transmisión de las 21 a las 22 horas, además de todas las limitantes establecidas para las bebidas alcohólicas se agregó que no pueden patrocinar eventos deportivos.

Los fabricantes de tabacos se comprometieron a acatar lo establecido en el Reglamento de Publicidad en Materia de Salud, en su código de autorregulación plantean el respeto al nuevo horario establecido y a respetarlo tanto en radio como en televisión; realizar una campaña para que no se vendan cigarros a menores de edad, no colocar anuncios espectaculares a menos de 200 metros cerca de escuelas, también señalan que no pagarán por que sus productos aparezcan en series de televisión o en películas y sólo patrocinarán eventos para adultos.

La autorregulación de los fabricantes de tabacos parece limitada ante el atractivo que por años ha representado la publicidad y no toma mayores medidas ante lo 
que autoridades sanitarias han calificado como "un serio problema de salud", con alto incremento en la mortalidad y una fuerte tendencia en el aumento de fumadores, a pesar de las restricciones para la venta del producto a menores de edad. De continuar la tendencia, para el año 2030, "una de cada seis personas morirá víctima del tabaco", señala Pablo Kuri, director de Epidemiología de la SSA y a esto se suma el dato de que en los últimos años ha disminuido la edad en que se empieza a fumar: 8.7 por ciento de los adictos al tabaco tienen entre 12 y 17 años de edad..$^{15}$

Francisco Espinoza, presidente de la Cámara de la Industria del Tabaco, expresó respecto a la campaña que promoverán las tabacaleras: "No queremos que nuestros niños y jóvenes fumen, los cigarros son para adultos que están bien informados sobre lo que están consumiendo en pleno uso de sus facultades". Sin embargo, esos adultos no han estado bien informados y han sido sometidos a atractivos mensajes con imágenes sociales que muestran al hombre de mundo, al hombre internacional, donde la propuesta de fumar se ha vinculado a la sexualidad, a la emancipación, a la madurez y a rituales privados y sociales. El psicólogo Fernando Dogana escribía hace años, que si se colocara un instructivo en los paquetes de cigarros con las indicaciones, como se hace con las medicinas, se podría leer: "Contra el aburrimiento, contra el miedo, contra el frío o el calor, contra la disciplina, contra la injusticia, contra la ira, contra la soledad, contra la timidez, sustituto del amor, de la libertad, del descanso; bueno para olvidar, para regocijarse, para inspirarse, bueno para pensar y para no pensar en nada, bueno para soportar al prójimo o para acercarse a él". ${ }^{16}$

\section{La publicidad de medicamentos}

Las tres palabras de "mejor, mejora, mejoral", han sido citadas como un ejemplo de las trilogías de la publicidad por Eulario Ferrer; esta es una antiquísima publicidad desde los tiempos en que la radio no competía aún con la televisión. Después, en la TV era frecuente encontrar a "la burbujita" de la sal de uvas, que volaba al estilo de la campanita de Peter Pan; el cariño de mamá materializado en una frotadita de Vaporub o con un Desenfriolito; más tarde vino la publicidad de Alka Seltzer, ya ambientado con bailarinas tropicales y con pegajosas canciones; más allá de estos, que se convirtieron con el tiempo de muestras clásicas de anuncios publicitarios, no era posible encontrar ningún otro medicamento que se hiciera una publicidad amplia en los medios electrónicos.

15. Milenio, 25 de julio del 2000.

16. Dogana, Fernando. Psicopatología del consumo cotidiano. Ed. Gedisa, Barcelona, 1984. p. 58. 
Desde hace unos cuantos años esto cambió. Al modificarse el Reglamento de Control Sanitario de la Publicidad, a finales del sexenio salinista, que estableció como publicidad masiva "aquella que se dirige al público en general de medicinas que no requieren receta médica para su venta"; esto significó, que muchos medicamentos no se vieran limitados a ser anunciados en revistas médicas, para conocimiento de los especialistas, sino que podían acceder a medios masivos de comunicación. Así, hoy en día es posible ver desde esos anuncios ya mencionados, hasta todo tipo de jarabes para la tos, medicamentos para las agruras, para la fiebre, para combatir infecciones vaginales, para molestias estomacales, antigripales y tabletas para calmar el dolor de cabeza urbano.

Este fenómeno tiene que ver con la desregulación en materia de publicidad, pero también con la abierta competencia a raíz de la firma del Tratado de Libre Comercio de los grandes laboratorios extranjeros, que buscan aconsejar al televidente de cual producto sirve para calmar algún tipo de molestia. Esto, en un país donde el consumidor se informa poco y donde ha sido común automedicarse, resulta en extremo riesgoso para la salud. Es conocido que ante cierto tipo de malestares es frecuente recurrir al consejo de los familiares o amigos o repetir lo que alguna vez el médico recetó; además de ello, ahora los medios de difusión asumen el papel de consejeros y sugieren de manera llamativa cual producto cura mejor. La única limitante de este tipo de publicidad es incluir una leyenda que señala "consulte a su médico", lo cual evidentemente sólo se hace cuando hay complicaciones.

Contradictoriamente, el Reglamento de Publicidad señala que la publicidad masiva "no podrá promover el consumo de los productos", lo cual es la idea contraria de la publicidad. Probablemente se habrá querido decir que se limitará a informar sobre las características del producto, pero en su mayoría este tipo de publicidad parte de mostrar una situación desagradable y culmina con situaciones de familias felices o de personas que muestran sensación de alivio inmediato y vuelven a sus actividades como si nada hubiera pasado.

Ha sido frecuente explotar el atractivo de la imagen fotográfica en las revistas o las cualidades del mensaje audiovisual en la televisión, para anunciar productos de higiene, belleza y aseo, generalmente esto no pasaba de promocionar jabones o cremas que prometian belleza, atractivo, juventud o el famoso "cutis de porcelana"; tintes para el cabello que hacían rejuvenecer al ocultar las canas o crear una nueva imagen, "es un pequeño lujo, pero creo que lo valgo"; perfumes o cosméticos cuya mayor promesa de venta era ganar amor o volverse irresistible a los ojos de los hombres. Es decir, lo más que podía resultar si la publicidad no era cierta, era una gran decepción, porque el producto ni había quitado las arrugas ni había logrado que uno conquistara al 
hombre de su vida, no había mayores consecuencias que la sensación de haber creído en soluciones mágicas, pero fuera de esto no había daños a la salud física.

Actualmente, junto con la proliferación de la publicidad de medicamentos, también se observa el gran número de anuncios de productos para adelgazar, contra la obesidad, para disminuir o hacer crecer alguna parte del cuerpo, tratamientos para el cabello, para las arrugas, para las estrías, para aclarar la piel, fajas, almohadas y productos bajos en calorías; todo aquello que corresponda a la búsqueda del ideal vigente de belleza: la juventud y la delgadez, como norma en la sociedad occidental contemporánea y del modelo globalizado, que proviene de empresas que venden todo tipo de productos por el sistema de telemarketing. En este tipo de publicidad, se presentan algunas leyendas, en letras pequeñas, que previenen sobre la existencia de ciertas dolencias o enfermedades que son incompatibles con el producto, pero que muchas veces por el tipo de la letra y la brevedad de su aparición no son atendidas por el televidente. Esto plantea otro aspecto de un problema, tal publicidad no es de medicamentos, pero sí de artículos que pueden representar un riesgo para la salud si no se utilizan adecuadamente y sin atender contraindicaciones médicas; usualmente la señora que va a adquirir una faja o un tratamiento adelgazante no le pregunta a su médico, ni tampoco lo hace el comprador de un aparato para hacer ejercicio para reducir el abdómen o agrandar el volúmen muscular.

$\mathrm{Ni}$ la ética publicitaria se aplica en estos casos, ni la reglamentación vigente se cumple; todavía existe la Ley del Consumidor que en su Título Tercero advierte sobre que la publicidad debe ser veraz y comprobable y no inducir a error o confusión. El actual Reglamento de Publicidad establece que deberán señalarse precauciones y riesgos de uso en la publicidad masiva; todo esto poco se respeta y resulta uno de los ejemplos clásicos de mayor riesgo en sociedades con bajos niveles de educación y cultura, donde el Estado ha abandonado su papel regulador y ha dejado libre a las reglas del mercado algo tan delicado como la salud de un gran número de consumidores.

El avance de la desregulación se ha dado en forma concertada entre anunciantes y agencias de publicidad y en correspondencia con la tendencia mundial. Las acciones que pugnan por la autorregulación de los propios publicistas, al estilo de Brasil, donde el Estado no interviene. El proyecto neoliberal vigente reafirma la tendencia de regirse por las leyes del mercado y frenar la participación del sector público, deja abierto el campo para conseguir a futuro manejarse sin restricciones. En estas condiciones, las modificaciones a la reglamentación en materia de publicidad apuntan en este sentido, no se avanza en una ley de publicidad integral que contemple otro tipo de publicidad que ha funcionado sin ninguna reglamentación (juguetes, bancos, 
aseguradoras, bienes raíces, llantas, etcétera). Correspondería a la sociedad civil avanzar en formas de autodefensa ante los mensajes publicitarios y tener una mayor participación para poder pasar a un régimen de autorregulación, sin este componente, permitir la autorregulación por parte de los anunciantes sería abandonar cualquier posibilidad futura de un ejercicio social de la publicidad, pues quienes participan en la industria publicitaria en México aún no han mostrado la madurez necesaria para actuar con responsabilidad ante la sociedad y no se han plegado ni al respeto de sus propios códigos éticos, como se observa al someterse cotidianamente a los mensajes publicitarios que los medios transmiten. 